Mirres, Plaves, and Concubines 


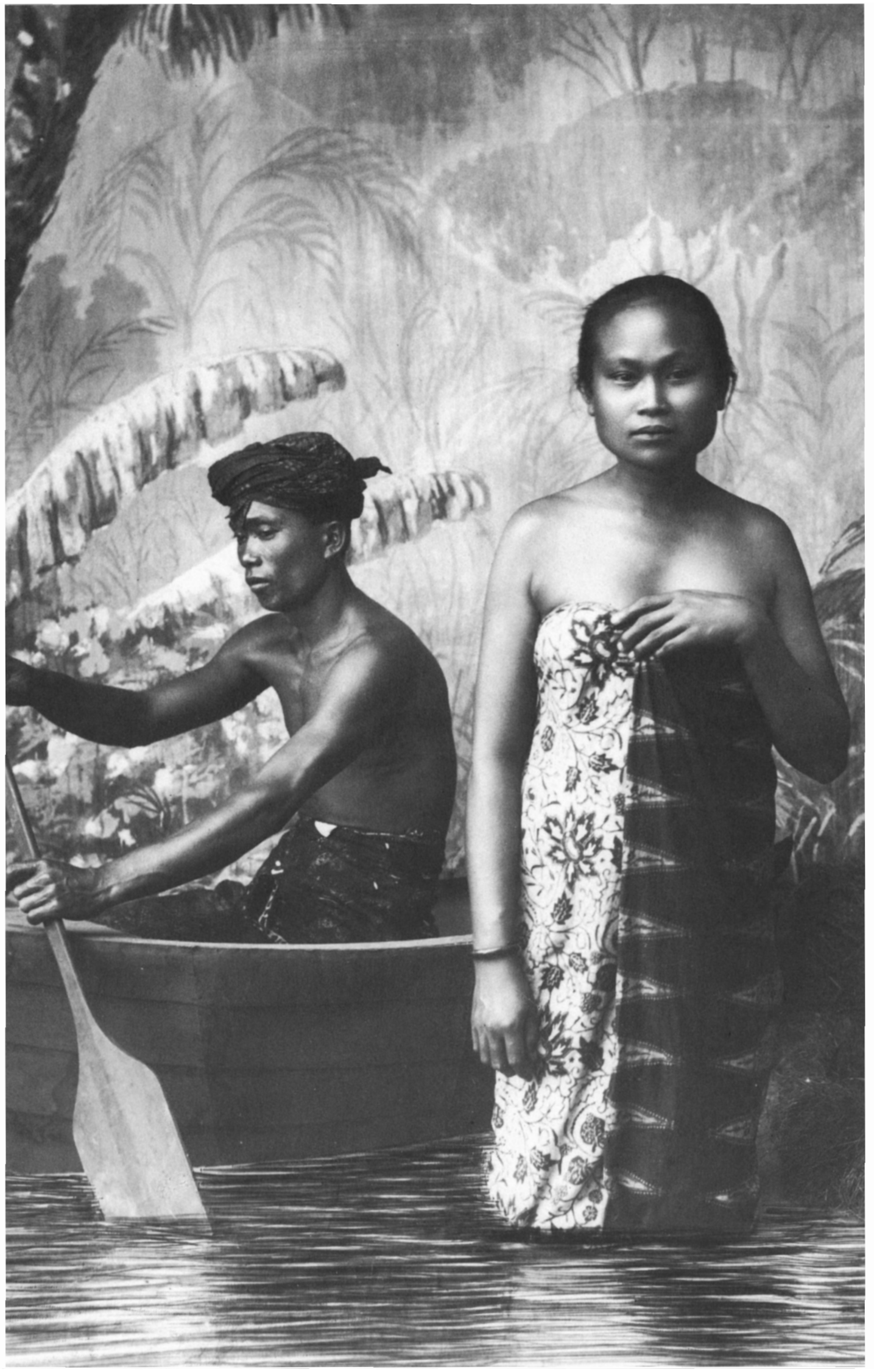




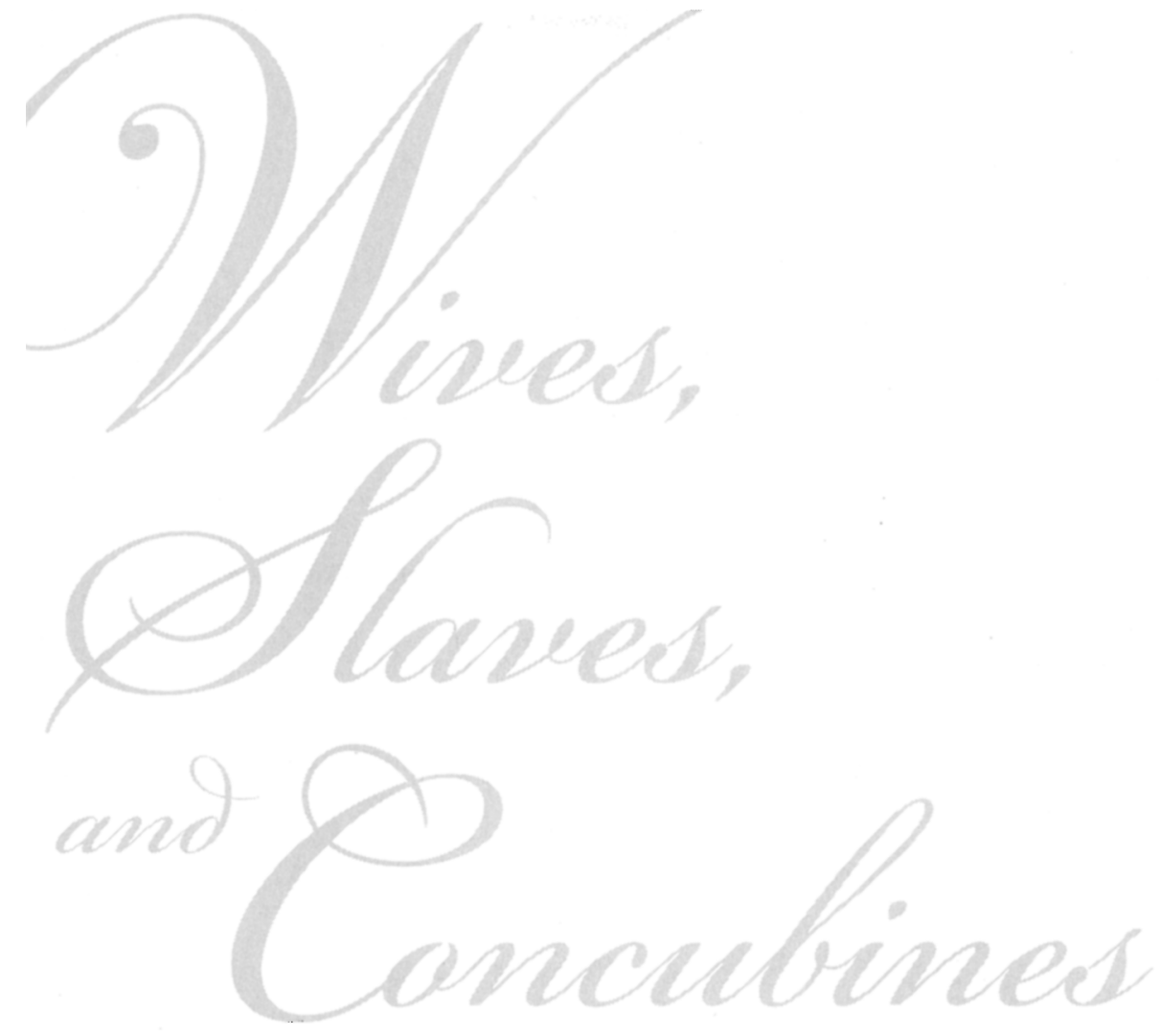
A History OF THE
FEMALE UNDERCLASS IN
D U T C H A I A

\section{Eric Jones}

TIm NORThern Illinois University PRess / DeKalb 
(C) 2010 by Northern Illinois University Press

Published by the Northern Illinois University Press, DeKalb, Illinois 60115

\author{
All Rights Reserved \\ Design by Julia Fauci
}

The photographs used throughout this book are from the John M. Echols Collection on Southeast Asia, Cornell University Library

Library of Congress Cataloging-in-Publication Data

Jones, Eric (Eric Alan)

Wives, slaves, and concubines: a history of the female underclass in Dutch Asia /

Eric Jones.

p. $\quad \mathrm{cm}$.

Includes bibliographical references and index.

ISBN 978-0-87580-410-1 (clothbound: alk. paper)

1. Women-Indonesia-Social conditions-18th century. 2. Wives-IndonesiaHistory-18th century. 3 . Women slaves-Indonesia-History-18th century.

4. Mistresses-Indonesia-History-18th century. 5. Concubinage-IndonesiaHistory-18th century. 6. Poor women-Indonesia-History-18th century.

7. Sex role-Indonesia-History-18th century. 8. Marginality, Social-IndonesiaHistory-18th century. 9. Indonesia-Social conditions-18th century.

10. Netherlands-Colonies-Asia-History-18th century. I. Title.

HQ1752.J66 2010

$305.48^{\prime} 96240959809033-\mathrm{dc} 22$

2009048452 
To Nyai Ontosoroh 
